\title{
DELIMITACIÓN Y CARACTERIZACIÓN DE LOS NUEVOS ESPACIOS URBANOS VALENCIANOS ${ }^{1}$
}

\author{
Julia Salom Carrasco \\ Juan Miguel Albertos Puebla \\ Departamento de Geografía. Instituto Interuniversitario de Desarrollo Local \\ Universidad de Valencia \\ Juan.M.Albertos@uv.es, Julia.Salom@uv.es
}

\section{RESUMEN}

La expansión urbanística, junto con la generalización de los procesos de descentralización residencial y económica, ha conducido a un nuevo modelo de ciudad dispersa caracterizado por la dificultad de establecer sus límites precisos. Utilizando un índice de densidad de ejes viarios procedente de una fuente comercial, y por tanto fácilmente actualizable, se ha delimitado el fenómeno urbano en la Comunidad Valenciana. Se discute la utilidad de la metodología y su capacidad para captar y caracterizar el hecho urbano a partir del contraste con la cartografía de usos del suelo de Corine.

Palabras clave: Áreas urbanas, Dispersión urbana, SIG, redes, usos del suelo, urbanización difusa.

\section{ABSTRACT}

Urban expansion, along with the generalization of the processes of residential and economic decentralization has led to a new model of urban sprawl characterized by the difficulty of establishing its precise boundaries. Using a density index of roads from a commercial source, and therefore easily upgradeable, it has been defined the phenomenon in the Comunidad

Fecha de recepción: febrero 2012.

Fecha de aceptación: diciembre 2012.

1 Este trabajo se ha elaborado en el marco del proyecto de investigación financiado por el Plan Nacional de I+D del Ministerio de Ciencia e Innovación titulado: Sostenibilidad ambiental y social en espacios metropolitanos. El caso del Área Metropolitana de Valencia (CSO2010-20481). Una versión inicial de la primera parte de este artículo fue presentada en el XXII Congreso de la Asociación de Geógrafos Españoles celebrado en octubre de 2011 en Alicante. 
Valenciana. The usefulness of the methodology and its ability t capture and to characterize the urban reality is discussed using the Corine land use cartography.

Key words: Urban areas, Urban sprawl, GIS, road networks, land use.

\section{INTRODUCCIÓN}

Desde poco antes del cambio de siglo y hasta fechas muy recientes, la coyuntura económica, la dinámica turística y la política urbanística han favorecido en España un crecimiento desmesurado del espacio urbanizado de importantes consecuencias ambientales, sociales y territoriales. Uno de los rasgos característicos de este crecimiento es el gran peso que tienen los modelos morfológicos de baja densidad frente al anterior predominio de los modelos de ciudad compacta. La generalización de los procesos de descentralización residencial y económica y el aumento de la movilidad han llevado a la dispersión urbana sobre el territorio, extendiéndose nuevos modelos de organización física de las áreas residenciales que han llevado a hablar de «ciudad difusa» o «ciudad sin límites» (Indovina, 1998; Nel.lo, 1996). En las áreas litorales, la urbanización turística ha dado lugar también a una forma particular de urbanización difusa, concretada en una conurbación litoral constituida por una serie de espacios urbanizados fragmentarios, carentes de una verdadera articulación urbana.

La Comunidad Valenciana es una de las regiones españolas que de forma más intensa ha experimentado este incremento del suelo urbanizado. Así, de acuerdo con los datos del proyecto Corine Land Cover, entre 1987 y 2000 el incremento del suelo sellado, urbanizado o artificial en la Comunidad Valenciana fue del 52'1\%, por encima tanto de la media nacional como europea. Una parte mayoritaria de este crecimiento se ha producido en las periferias urbanas y en los espacios interurbanos, generando la expansión física de las ciudades y dando lugar a la formación de espacios urbanos más extensos y laxos; pero también aparecen importantes ejemplos de carácter discontinuo ubicados en zonas relativamente alejadas de las áreas urbanas tanto a lo largo del litoral como en áreas interiores. Los procesos de suburbanización han afectado no sólo a las capitales provinciales, sino también a núcleos intermedios como Alcoi, Benidorm, Dénia o Xàtiva. En el caso del Área Metropolitana de Valencia, el fenómeno va alcanzando a zonas cada vez más alejadas de la ciudad central. La difusión del crecimiento, favorecido y guiado por los ejes viarios -carreteras a Madrid (A-3), a Ademuz (CV-35) y a Teruel (A-23) - alcanza ya a la Hoya de Buñol, e incluso a municipios de la comarca de los Serranos entre Llíria y Chelva. Además de los factores sociales y económicos, la práctica urbanística ha favorecido este modelo de crecimiento disperso, al primar criterios que rompen con la lógica del modelo de ciudad compacta (Navarro Vera et al., 2000).

En consecuencia, el 41'4\% del crecimiento de suelo artificial que se produjo en la región entre 1987 y 2000 correspondió al aumento de las zonas urbanas, especialmente las caracterizadas por un modelo disperso y de baja densidad; así, las urbanizaciones exentas o ajardinadas lo hicieron en un $48 \%$ y las estructuras urbanas laxas un $103,5 \%$, mientras que el tejido urbano compacto crecía en este periodo sólo un 8,5\% (Observatorio de la Sostenibilidad de España, 2006: 345 y 346). 
¿Cómo delimitar para su estudio estos nuevos espacios urbanos? La formación de este nuevo modelo de ciudad dispersa caracterizado por la dificultad de establecer un límite preciso para el entorno urbano implica nuevas dificultades para la medición y análisis del fenómeno urbano, el establecimiento de tipologías y conclusiones sobre procesos, dinámicas, problemas, etc., en distintos tipo de ciudades; aspectos todos ellos relevantes para elaborar propuestas de ordenación suficientemente sustentadas.

Existen distintos criterios que es posible aplicar a la hora de delimitar las áreas urbanas, siendo habitual diferenciar entre tres tipos de métodos: Los que utilizan indicadores indirectos para identificar características sociales, económicas y demográficas que se asocian al espacio urbano; los basados en características morfológicas tales como la densidad del espacio construido, la continuidad del área urbanizada, el tipo de uso del suelo predominante, etc.; y los que utilizan indicadores de la existencia de una relación funcional entre los núcleos de poblamiento, principalmente basados en la movilidad diaria entre el trabajo y la residencia de la población activa, pero también en otro tipo de desplazamientos o interrelaciones que permitan delimitar el espacio urbano como el ámbito de vida de sus habitantes. Tanto los primeros como los últimos, que hemos aplicado en ocasiones anteriores a este mismo ámbito geográfico (Salom et al. 1997; Salom y Casado, 2007), tienen como principal problema el hecho de que la base estadística utilizada viene referida habitualmente al término municipal, lo que impide establecer los límites del fenómeno urbano de forma precisa. Por otra parte, la delimitación morfológica tradicional ha mostrado claras limitaciones a la hora de acotar los espacios urbanos discontinuos característicos de muchas aglomeraciones urbanas actuales (Salom, 2011).

En esta ocasión aplicaremos un método de delimitación incluido dentro del grupo basado en criterios morfológicos, pero que consideramos mejor adaptado a las características actuales del fenómeno urbano, ya que pretende tener en cuenta tanto los espacios urbanos continuos como los discontinuos. Partiendo de la hipótesis de que el crecimiento urbano mantiene una estrecha relación bidireccional con la red de comunicaciones (Miralles, 2002), realizamos una aproximación a la delimitación de las áreas urbanizadas utilizando una serie de índices relacionados con la densidad de las redes de comunicación. La hipótesis de partida es que las interacciones espaciales definidas por distintos tipos de red, y entre ellas por la red física de comunicaciones, se encuentran en la base de la definición del nuevo concepto de ciudad. Se trataría, pues, de un método de delimitación de tipo morfológico, pero más adaptado al nuevo modelo de ciudad en tanto que apunta indirectamente a la relación funcional entre espacios.

\section{OBJETIVOS Y METODOLOGÍA}

El objetivo de este artículo es describir y analizar el fenómeno urbano actual en la Comunidad Valenciana mediante un método de delimitación basado en criterios morfológicos, pero adaptado a los nuevos procesos, que permita definir las características actuales del fenómeno urbano teniendo en cuenta tanto los espacios urbanos continuos como los discontinuos.

La delimitación que aquí aplicamos se basa en la desarrollada en Salom y Albertos (2010), que a su vez se inspira en el trabajo de Borruso (2003) para la delimitación de espacios urbanos en Reino Unido e Italia. La hipótesis de partida es que la densidad de ejes 
de comunicación viarios (calles, carreteras), medida a partir del número de intersecciones (nodos) de la red es un indicador del volumen de flujos y está estrechamente relacionado con la existencia de una morfología urbana. Es decir, que las áreas urbanas se caracterizan por una red de comunicaciones que presenta una mayor densidad de intersecciones a la de las áreas no urbanas. De acuerdo con esta hipótesis, sería posible utilizar índices de densidad de intersecciones de la red para definir los límites del contorno urbano y, por ende, analizar su evolución y dinámica de crecimiento.

Se trata de una metodología de carácter fundamentalmente morfológico que, sin embargo, recoge también una dimensión funcional en la medida en que se puede asociar el hecho urbano a una mayor densidad de las redes viarias, y por ende, de flujos. Como delimitación de raíz morfológica permite una mayor precisión al utilizar como base el espacio construido -y no el conjunto de los términos municipales- y la agregación de espacios no estrictamente contiguos. Al mismo tiempo, complementa la visión de las delimitaciones más puramente funcionales basadas en flujos como el de residencia-trabajo que han sido desarrolladas y aplicadas en España en los últimos años con diferentes objetivos: delimitación de áreas de cohesión (Castañer, 1994; Salom, Albertos, Delios y Pitarch, 1996), de áreas de mercado de trabajo local (Salom, Albertos, Delios y Pitarch, 1997; Salom y Casado, 2007), o de áreas metropolitanas (Feria, 2008).

La información de base es la cartografía de intersecciones reales de la red de comunicaciones terrestres incluida en la base de datos Multinet Spain de la empresa Teleatlas, que contiene información actualizada con fecha de julio de 2007 en formato shape -utilizable por tanto por los principales programas de SIG- de la red de carreteras de toda España clasificada en ocho niveles, desde los grandes ejes de conexión intermetropolitanos hasta las calles secundarias de los centros urbanos ${ }^{2}$. Consideramos que esta base de datos, por sus aplicaciones y su finalidad comercial, pretende ser exhaustiva y está constantemente en proceso de actualización, por lo que puede ser útil para revisar periódicamente los resultados de la delimitación y establecer comparaciones temporales, permitiendo así un seguimiento de los procesos de urbanización. El uso de nuevos tipos de fuentes de datos, muchas de ellas de origen comercial pero con una mayor frecuencia de actualización, en combinación con otros datos de origen más convencional, es un planteamiento que se ha considerado útil para modelizar y comprender los sistemas urbanos (Harris y Longley, 2000). La información procedente de esta fuente fue contrastada con la cartografía de usos del suelo definido a partir de clasificación de imágenes de satélite (Corine Land Cover Spain, 2000).

La metodología desarrollada consta de cuatro pasos: a) Selección y cálculo de índices de densidad de la red. b) Definición de umbrales asociados a cada tipo de uso del suelo. c) Delimitación de los espacios urbanos a partir de los umbrales detectados en el paso anterior

2 No hemos detectado en nuestro análisis una presencia reseñable de redes viarias «no funcionales», es decir, de redes correspondientes a espacios urbanos en construcción pero todavía no ocupados. El año de referencia de la cartografía de la red viaria aquí empleado, 2007, previo al estallido de la conocida como «burbuja inmobiliaria», ha contribuido a ello. No obstante, en el momento actual esta situación puede ser importante en algunas periferias de áreas metropolitanas, lo que aconsejaría en estos casos la aplicación de un filtro previo a partir de la cartografia de usos del suelo para eliminar estos espacios en construcción. 
y agregación de los más próximos ${ }^{3}$, y d) Caracterización de los espacios urbanos y detección de tipologías asociadas a distintos procesos de crecimiento urbanístico. El análisis se realizó mediante el uso de sistemas de información geográfica ${ }^{4}$. En trabajos anteriores, la aplicación de esta metodología a la delimitación de ocho áreas urbano-metropolitanas españolas ${ }^{5}$ permitió concluir que el índice de densidad kernel con un radio de búsqueda de $500 \mathrm{~m}$. sobre una cuadrícula de $25 \mathrm{~m}$. de resolución era el más adecuado para la delimitación del contorno urbano general, siendo el ajuste máximo con el contorno del tejido urbano continuo según CORINE. De hecho, el indicador de densidad de red permitía incluso recoger con gran precisión los espacios urbanos continuos de los pequeños núcleos urbanos que, por su menor superficie, quedan mal reflejados en el mapa de usos del suelo elaborado por teledetección. El índice recogía también, aunque de forma menos eficiente, el tejido urbano discontinuo identificado a partir de la imagen de satélite; por el contrario, no se considera adecuado para detectar espacios industriales y comerciales a no ser que se encuentren adosados o muy próximos al continuo urbano.

Por otra parte, el análisis de la relación entre los índices de densidad de red y los usos del suelo en las siete provincias en donde se ubicaban los casos de estudio nos permitió detectar, pese a las diferencias de modelos y morfologías urbanas, algunos umbrales de densidad de la red que permitieran identificar el tejido urbano tanto continuo como discontinuo, diferenciándolo en la medida de lo posible los usos artificiales de los no artificiales. De todos ellos, los valores más adecuados cuando el objetivo es recoger con la mayor amplitud posible cualquier tipo de espacio urbano, sea de carácter continuo o discontinuo, son los de $100 \mathrm{y}$ 40 intersecciones $/ \mathrm{km}^{2}$. El primero recoge la práctica totalidad de los espacios urbanos continuos, aunque deja fuera una parte importante de los espacios urbanos discontinuos, mientras que el segundo los incluye a ambos, así como a una parte significativa de los espacios industriales y comerciales. En síntesis, la aplicación del índice 100 da como resultado un área de carácter urbano y/o metropolitano, reflejando principalmente el resultado de los procesos de urbanización continua mejor ajustados al concepto tradicional de ciudad-área urbanaárea metropolitana, mientras que el índice 40 permite delimitar «continuos» urbanos, incluyendo áreas de urbanización dispersa principalmente de carácter residencial, aunque también recoge algunos procesos de carácter industrial y comercial y conurbaciones derivadas de la coalescencia de núcleos pequeños y medianos próximos al área metropolitana.

Los índices nos permitieron también caracterizar las diferencias provinciales en relación con la morfología del espacio construido. En este sentido, la provincia de Valencia es la

3 En términos generales, se consideraron como continuos urbanizados las áreas de municipios limítrofes con una separación entre periferias (residenciales, industriales y de servicios) inferior a $1 \mathrm{Km}$., distancia que habitualmente se considera coincidente con la isocrona de 15 minutos en viajes a pie, exponentes por excelencia de la movilidad urbana (Conselleria d'Obres Públiques, 1995, p. 3).

4 Se utilizó el programa ArcGis 9.2 de Esri, y en particular el módulo Spatial Analyst para el cálculo de los índices de densidad Kernel, la interpolación y manipulación de las isolíneas y el cálculo zonal necesario para el análisis estadístico de los resultados. La metodología se describe con detalle en Salom y Albertos (2010).

5 Las áreas analizadas fueron Madrid, Barcelona, Valencia, Sevilla, Bilbao, Girona, Cádiz y Oviedo. La selección respondía al objetivo de verificar la metodología con distintos tipos de áreas por tamaño y forma urbana (grandes áreas metropolitanas y ciudades medianas; áreas polinucleares o concentradas, con mayor o menor proceso de suburbanización). 
que presenta un modelo urbano menos compacto de las siete provincias estudiadas ${ }^{6}$, siendo también la que ofrece una mayor variabilidad de situaciones, sobre todo en relación al suelo urbano disperso. Así, mientras que en las provincias de Sevilla, Madrid y Cádiz entre el 40 y el $50 \%$ del suelo urbano continuo tiene índices de densidad superiores a 300, en la provincia de Valencia sólo el 27'6\% alcanza esta cifra. Las diferencias en relación al suelo urbano discontinuo van también en este sentido: El 62\% de este tipo de suelo tiene índices de densidad menores de 100 en la provincia de Valencia, frente al 32'9\% de Madrid o al 49'3\% de Barcelona.

En el presente trabajo aplicamos la metodología descrita al conjunto de la Comunidad Valenciana, con el fin de obtener una delimitación de los espacios urbanos valencianos que incluya tanto los espacios de urbanización continua como difusa.

\section{RESULTADOS Y DISCUSIÓN}

\section{Delimitación de «Áreas» y de «Continuos» Urbanos}

Se pretende realizar una delimitación y caracterización del fenómeno urbano adaptada a los nuevos procesos de crecimiento que permita analizar el fenómeno de la «ciudad difusa» en la Comunidad Valenciana, una de las regiones españolas que ha experimentado un crecimiento urbanístico más intenso en los últimos años. La aplicación da como resultado que en los primeros puestos por superficie ocupada aparecen junto con las áreas metropolitanas y urbanas más importantes, los continuos urbanizados del litoral y las áreas dispersas de las periferias metropolitanas, por lo que «a priori» podemos considerar que el objetivo principal ha sido alcanzado.

Tabla 1

PRINCIPALES CARACTERÍSTICAS DE LAS DELIMITACIONES

\begin{tabular}{|l|c|c|}
\hline & $\begin{array}{c}\text { Áreas Urbanas } \\
\text { (umbral 100) }\end{array}$ & $\begin{array}{c}\text { Continuos Urbanos } \\
\text { (umbral 40) }\end{array}$ \\
\hline Número de áreas & 603 & 631 \\
\hline Número de áreas supramunicipales & 122 & 107 \\
\hline Superficie ocupada total (Has) & 88500 & 297640 \\
\hline Superficie media (Has.) & 147 & 472 \\
\hline$\%$ del territorio regional & $3.8 \%$ & $12.8 \%$ \\
\hline
\end{tabular}

Fuente: Elaboración propia a partir de Teleatlas y CLC 2006

La aplicación de la metodología expuesta al caso de la Comunidad Valenciana permite la delimitación y caracterización tanto de Áreas Urbanas (umbral 100) como de Continuos Urbanos mucho más amplios (umbral 40) (Cuadro 1). Aunque se ha individualizado un

6 La provincia de Vizcaya no se incluyó en el análisis provincial al incorporarse el estudio del área urbana de Bilbao en una fase posterior del trabajo. 
número similar de Áreas y de Continuos Urbanos, estos últimas tienen una superficie media muy superior, ya que la disminución del umbral de densidad (a 40) lleva a considerar como urbanos espacios que en el anterior umbral (100) no lo eran, al tiempo que la agregación de espacios se hace más frecuente. De esta manera, en su conjunto el espacio total delimitado como perteneciente a Continuos Urbanos es muy superior al englobado en las áreas urbanas, hasta alcanzar casi el $13 \%$ de todo el territorio regional.

La delimitación correspondiente a las Áreas Urbanas permite identificar espacios conurbados a partir de la red del viario que pueden ser consideradas unidades de análisis más

Tabla 2

PRINCIPALES ÁREAS URBANAS DELIMITADAS: CARACTERÍSTICAS

\begin{tabular}{|c|c|c|c|c|c|c|}
\hline \multirow[b]{2}{*}{$\begin{array}{l}\text { Área } \\
\text { Urbana }\end{array}$} & \multirow[b]{2}{*}{$\begin{array}{c}\text { Superficie } \\
\mathbf{K m}^{2} \\
\end{array}$} & \multirow[b]{2}{*}{$\begin{array}{c}\% \text { Superficie } \\
\text { artificial }\end{array}$} & \multicolumn{4}{|c|}{ Distribución porcentual de la superficie artificial } \\
\hline & & & $\begin{array}{c}\text { Tejido } \\
\text { urbano } \\
\text { continuo }\end{array}$ & $\begin{array}{l}\text { Tejido } \\
\text { urbano dis- } \\
\text { continuo }\end{array}$ & $\begin{array}{c}\text { Zonas indus- } \\
\text { triales y } \\
\text { comerciales }\end{array}$ & Resto \\
\hline Valencia & 156,6 & $80 \%$ & $55 \%$ & $20 \%$ & $17 \%$ & $7 \%$ \\
\hline Alicante & 53,1 & $74 \%$ & $51 \%$ & $32 \%$ & $12 \%$ & $5 \%$ \\
\hline Torrevieja & 32,9 & $87 \%$ & $20 \%$ & $70 \%$ & $4 \%$ & $6 \%$ \\
\hline Gandia & 30,5 & $58 \%$ & $72 \%$ & $11 \%$ & $8 \%$ & $9 \%$ \\
\hline Calp & 19,4 & $93 \%$ & $3 \%$ & $93 \%$ & $0 \%$ & $4 \%$ \\
\hline Castellón & 17,4 & $83 \%$ & $56 \%$ & $7 \%$ & $27 \%$ & $11 \%$ \\
\hline Almoradí & 15,3 & $60 \%$ & $40 \%$ & $47 \%$ & $4 \%$ & $8 \%$ \\
\hline Alzira & 13,1 & $55 \%$ & $67 \%$ & $11 \%$ & $18 \%$ & $4 \%$ \\
\hline Ontinyent & 12,7 & $55 \%$ & $31 \%$ & $45 \%$ & $24 \%$ & $0 \%$ \\
\hline Altea & 12,5 & $78 \%$ & $17 \%$ & $83 \%$ & $0 \%$ & $0 \%$ \\
\hline Elda & 12,3 & $69 \%$ & $58 \%$ & $27 \%$ & $14 \%$ & $0 \%$ \\
\hline Elx & 11,8 & $87 \%$ & $57 \%$ & $10 \%$ & $24 \%$ & $10 \%$ \\
\hline $\begin{array}{l}\text { Callosa de } \\
\text { Segura }\end{array}$ & 11,0 & $52 \%$ & $77 \%$ & $2 \%$ & $11 \%$ & $10 \%$ \\
\hline Carlet & 9,5 & $46 \%$ & $77 \%$ & $0 \%$ & $23 \%$ & $0 \%$ \\
\hline Xàtiva & 9,2 & $51 \%$ & $84 \%$ & $0 \%$ & $12 \%$ & $3 \%$ \\
\hline Xàbia & 8,2 & $93 \%$ & $20 \%$ & $78 \%$ & $2 \%$ & $0 \%$ \\
\hline Dénia & 7,7 & $90 \%$ & $25 \%$ & $68 \%$ & $5 \%$ & $2 \%$ \\
\hline Sagunt & 7,4 & $76 \%$ & $57 \%$ & $26 \%$ & $12 \%$ & $5 \%$ \\
\hline Total CV & 885,5 & $60 \%$ & $54 \%$ & $30 \%$ & $7 \%$ & $9 \%$ \\
\hline
\end{tabular}

Fuente: Elaboración propia a partir de Teleatlas y CLC 2006. 
Figura 1

PORCENTAJE DEL TEJIDO URBANO DISCONTINUO SOBRE EL TEJIDO URBANO TOTAL EN LAS ÁREAS URBANAS DELIMITADAS

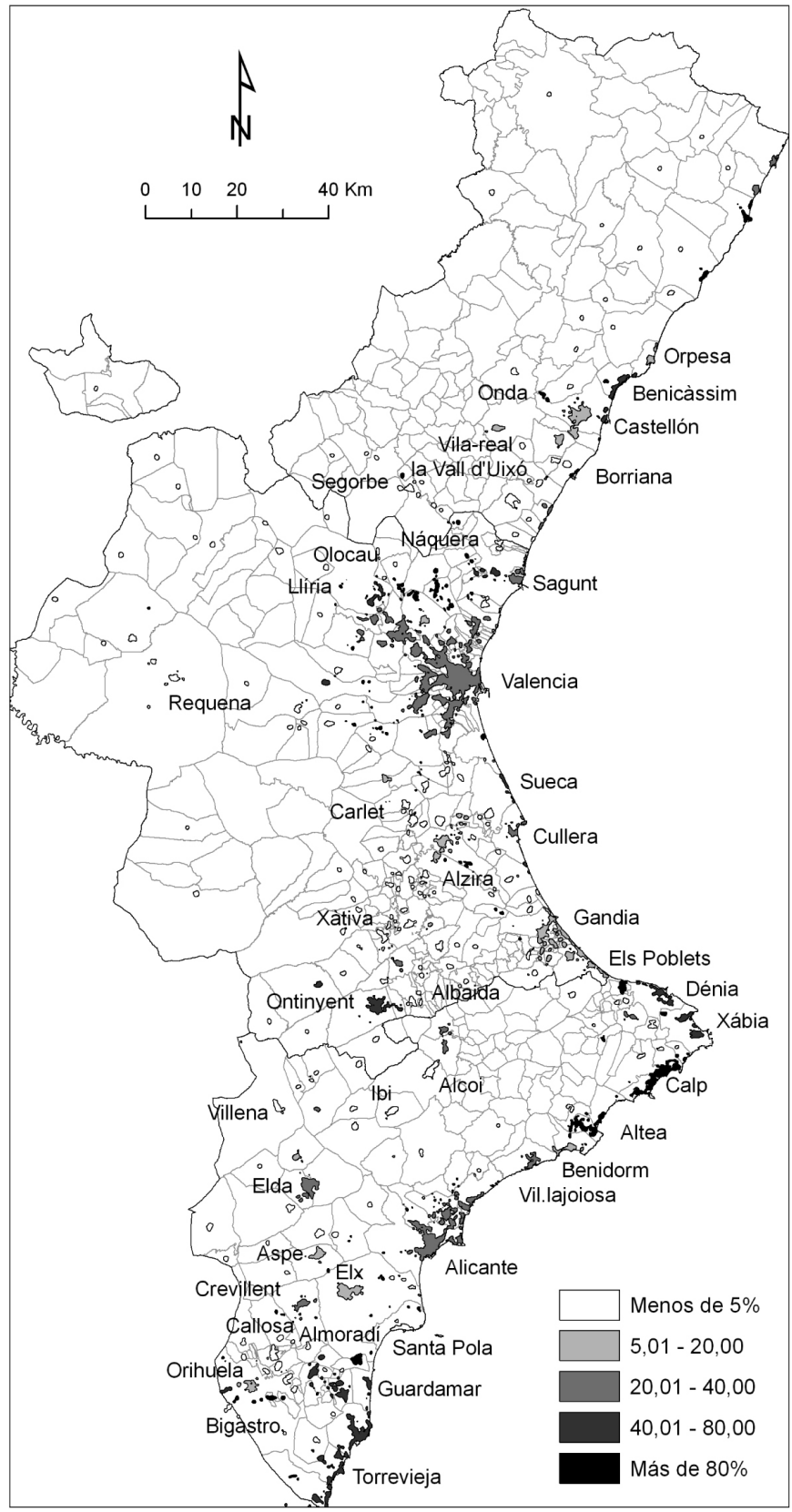

Fuente: Elaboración propia a partir de Teleatlas y CLC 2006. 
Tabla 3

PRINCIPALES CONTINUOS URBANOS DELIMITADOS: CARACTERÍSTICAS

\begin{tabular}{|c|c|c|c|c|c|c|c|c|}
\hline \multirow[b]{2}{*}{$\begin{array}{l}\text { Continuo } \\
\text { Urbana }\end{array}$} & \multirow[b]{2}{*}{$\begin{array}{c}\text { Pob. } \\
\text { (miles) }\end{array}$} & \multirow[b]{2}{*}{$\begin{array}{c}\text { Superf. } \\
\mathbf{K m}^{2}\end{array}$} & \multirow[b]{2}{*}{$\begin{array}{c}\text { Densi- } \\
\text { dad } \\
\text { Habs/Ha }\end{array}$} & \multirow[b]{2}{*}{$\begin{array}{c}\% \\
\text { Superf. } \\
\text { artificial }\end{array}$} & \multicolumn{4}{|c|}{ Distribución \% de la superficie artificial } \\
\hline & & & & & $\begin{array}{c}\text { Tejido } \\
\text { urbano } \\
\text { continuo }\end{array}$ & $\begin{array}{c}\text { Tejido } \\
\text { Urbano } \\
\text { Disconti- } \\
\text { nuo } \\
\end{array}$ & \begin{tabular}{|c|} 
Zonas \\
industriales \\
y comer- \\
ciales
\end{tabular} & Resto \\
\hline Valencia & 2118 & 1083 & 20 & $28 \%$ & $40 \%$ & $31 \%$ & $21 \%$ & $8 \%$ \\
\hline Elx-Orihuela & 609 & 415 & 15 & $28 \%$ & $32 \%$ & $46 \%$ & $11 \%$ & $10 \%$ \\
\hline Gandia & 401 & 405 & 10 & $21 \%$ & $44 \%$ & $35 \%$ & $13 \%$ & $9 \%$ \\
\hline Alicante & 437 & 136 & 32 & $50 \%$ & $34 \%$ & $41 \%$ & $15 \%$ & $10 \%$ \\
\hline Benidorm & 192 & 80 & 24 & $49 \%$ & $25 \%$ & $64 \%$ & $4 \%$ & $7 \%$ \\
\hline Xàbia-Altea & 86 & 79 & 11 & $65 \%$ & $7 \%$ & $89 \%$ & $1 \%$ & $3 \%$ \\
\hline Castellón & 286 & 76 & 37 & $54 \%$ & $39 \%$ & $31 \%$ & $21 \%$ & $9 \%$ \\
\hline Elda-Petrer & 111 & 40 & 27 & $42 \%$ & $44 \%$ & $31 \%$ & $23 \%$ & $2 \%$ \\
\hline Santa Pola & 28 & 29 & 10 & $48 \%$ & $44 \%$ & $40 \%$ & $6 \%$ & $10 \%$ \\
\hline $\begin{array}{l}\text { Burriana- } \\
\text { Nules }\end{array}$ & 52 & 28 & 19 & $27 \%$ & $56 \%$ & $18 \%$ & $14 \%$ & $11 \%$ \\
\hline Alcoi & 82 & 27 & 30 & $38 \%$ & $63 \%$ & $16 \%$ & $17 \%$ & $4 \%$ \\
\hline Total CV & 4807 & 2976 & 16 & $29 \%$ & $38 \%$ & $39 \%$ & $15 \%$ & $9 \%$ \\
\hline
\end{tabular}

Fuente: Elaboración propia a partir de Teleatlas y CLC 2006.

apropiadas que las definidas a partir de criterios de tipo administrativo, ya que en principio podemos considerar que existe una cierta integración funcional.

En el Cuadro 2 se han reunido algunos datos básicos correspondientes a las 18 Áreas Urbanas más extensas (el nombre asignado hace referencia al municipio con mayor población). En conjunto, estas 18 áreas suman el 50\% del territorio delimitado.

La primera observación a destacar es que las principales áreas urbanas muestran una notable colmatación: las superficies artificiales ocupan porcentajes muy elevados del espacio delimitado, a menudo por encima del 70\%; es el caso de Alicante (74\%), Sagunt (76\%), Valencia (80\%), Castellón (83\%) o Elx (87\%). No obstante, es en algunas de las Áreas Urbanas litorales, con una fuerte presencia de actividades turísticas y residencias secundarias, en las que este nivel de «artificialización» es más acusado, como puede verse en los casos de Torrevieja (87\%), Dénia (90\%), Xàbia (93\%) o Calp (93\%). Por el contrario, la colmatación es menos intensa en las ciudades medias del interior: Alzira (55\%), Ontinyent (55\%), Elda (69\%), o Carlet (46\%).

En otro orden, puede observarse cómo la extensión de tejido urbano discontinuo, a menudo relacionado con un urbanismo de baja densidad, tiene su mayor presencia en dos tipo de áreas (ver Figura 1); en primer lugar, en los espacios litorales antes mencionados: Dénia (68\%), Torrevieja (70\%), Xàbia (78\%), Altea (83\%), Calp (93\%); y en segundo lugar, 
Figura 2

ÁREAS URBANAS INCLUIDAS EN EL CONTINUO URBANO DE VALENCIA

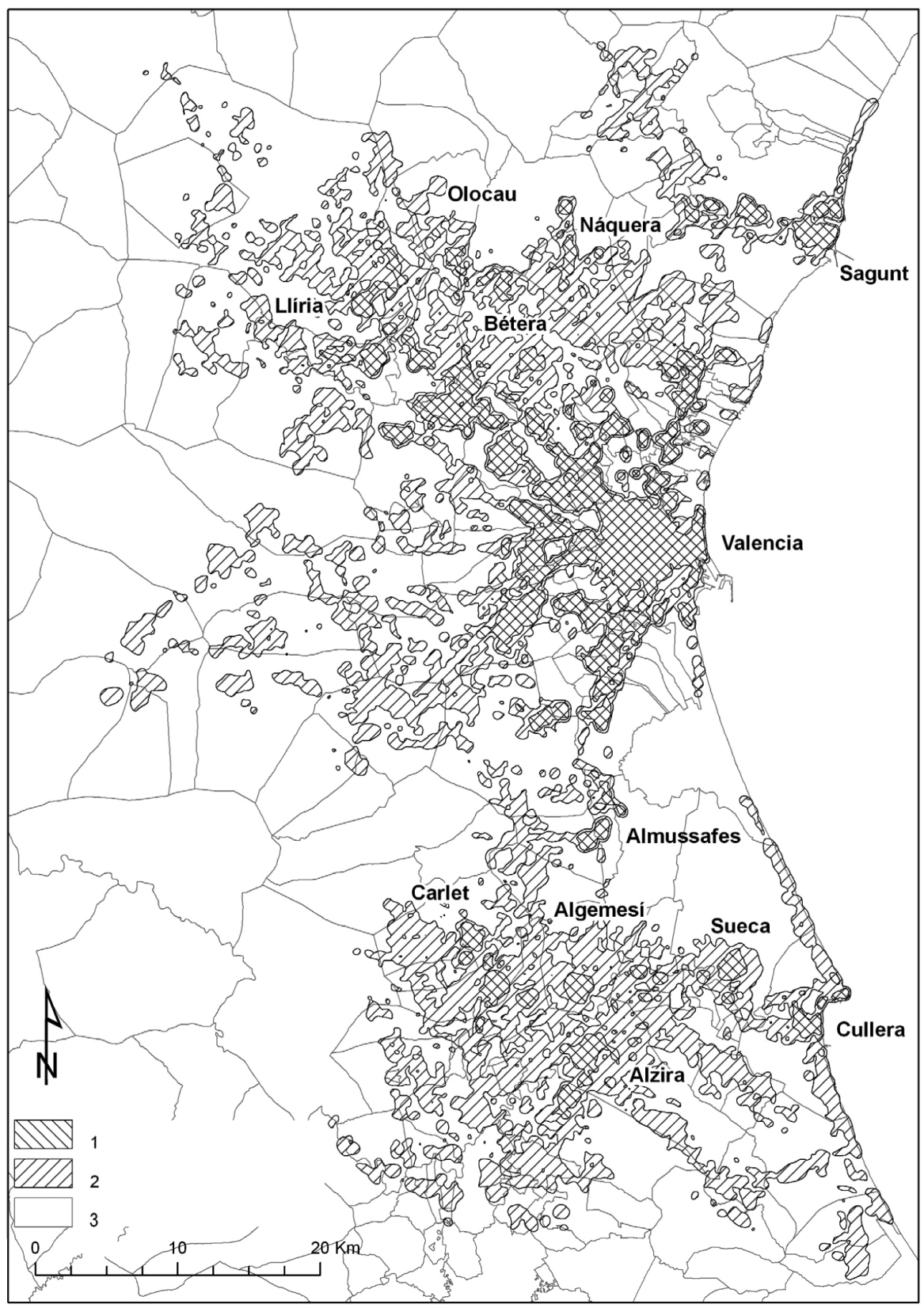

1.- Áreas urbanas, 2.-Continuo urbano de Valencia, 3.-Término municipal. Fuente: Elaboración propia a partir de Teleatlas. 
en las áreas urbanas más grandes, donde aunque su participación porcentual es menor, su tamaño absoluto resulta sensible: Valencia (20\%), Alicante (32\%).

La extensión de espacios de especialización funcional como los dedicados de forma exclusiva a funciones industriales o comerciales presenta importantes diferencias según Áreas Urbanas. En general, los máximos porcentuales se encuentran en las grandes Áreas Urbanas (Valencia, 17\%; Alicante, 12\%; Castellón, 27\%), junto a las ciudades medias de especialización industrial (Carlet, 23\%; Elx, 24\%; Ontinyent, 24\%). Estos elevados valores, ligados sea a actividades industriales, sea al desarrollo de nuevas áreas empresariales, de servicios, comerciales o de ocio, muestran la importante contribución de estas actividades a los procesos de consumo de suelo y crecimiento de la mancha urbana.

Por otra parte, las delimitaciones correspondientes a Continuos Urbanos permiten visualizar grandes estructuras territoriales determinadas por espacios urbanizados que, si bien son menos densos que las anteriores Áreas Urbanas, no carecen de cohesión. Ofrecen asimismo una visión de la escala que ha alcanzado el proceso de urbanización difusa, que en la Comunidad Valenciana afecta ya el $13 \%$ de todo el territorio (Tabla 3 ).

Los 11 Continuos Urbanos que se detallan en el Cuadro 3 suman el 80\% de la superficie total delimitada y superan el $90 \%$ de la población residente en la región. Constituyen grandes conjuntos urbanos, destacando especialmente el de Valencia, que, con más de 2 millones de habitantes y 1083 kilómetros cuadrados, llega por el norte hasta el Alto Palancia y la Plana Baixa (Castellón), por el sur hasta la Ribera del Xuquer y la Valldigna y por el oeste hasta el Camp de Turia y la Hoya de Buñol. La figura 2 muestra la extensión de este gran espacio urbanizado, señalando además las principales áreas urbano-metropolitanas que incluye: Sagunt, Llíria, Náquera, Olocau y Bétera en el norte; Almussafes, Carlet, Algemesí, Sueca, Cullera y Alzira en el sur.

Otros grandes conjuntos supracomarcales los constituyen los Continuos Urbanos de Orihuela-Elx (Bajo y Medio Vinalopó y Bajo Segura), y Gandia (Safor, Marina Alta, Costera y Vall d'Albaida). El primero de ellos, mostrado en la figura 3, es especialmente expresivo de la magnitud adoptada por los nuevos procesos urbanos, ya que desborda los límites regionales, fusionándose por el interior con el área urbana de Murcia y prolongándose por el litoral en los municipios murcianos de San Javier y Los Alcázares, así como, parcialmente, en el municipio de Torre-Pacheco. Este extenso continuo urbano incluye las áreas urbanas de Aspe, Elx, Crevillent, Guardamar del Segura, Orihuela, Callosa de Segura, Almoradí, Bigastro, Torrevieja y Murcia, así como un rosario de pequeños islotes urbanizados de baja densidad de los que sólo se representan en la figura adjunta aquéllos que alcanzan un tamaño significativo.

Por su parte, el continuo urbano de Gandia, que aparece representado en la figura 4, articula a través de tejidos urbanos discontinuos las áreas urbanas interiores de Xàtiva, Ontinyent y Albaida, así como, con modelos más densos, las litorales de Gandia, Els Poblets y Dènia.

Aunque el resto de Continuos Urbanos delimitados alcanza sólo la escala comarcal, debemos destacar por su interés los espacios correspondientes al litoral alicantino (Continuos Urbanos de Alicante, Benidorm, Xàbia, en la figura 5) y castellonense (Continuos Urbanos de Castellón, Borriana, Betxí, Onda, la Vall d'Uixó y Moncofa, en la figura 6), espacios polinucleares en las que los procesos de suburbanización y urbanización dispersa -más intensos en el primer caso que en el segundo- parecen abocados a formar a medio plazo extensas Continuos Urbanos similares a las mencionados en primer lugar. 
Figura 3

ÁREAS URBANO-METROPOLITANAS INCLUIDAS EN EL CONTINUO URBANO DE ORIHUELA-ELX

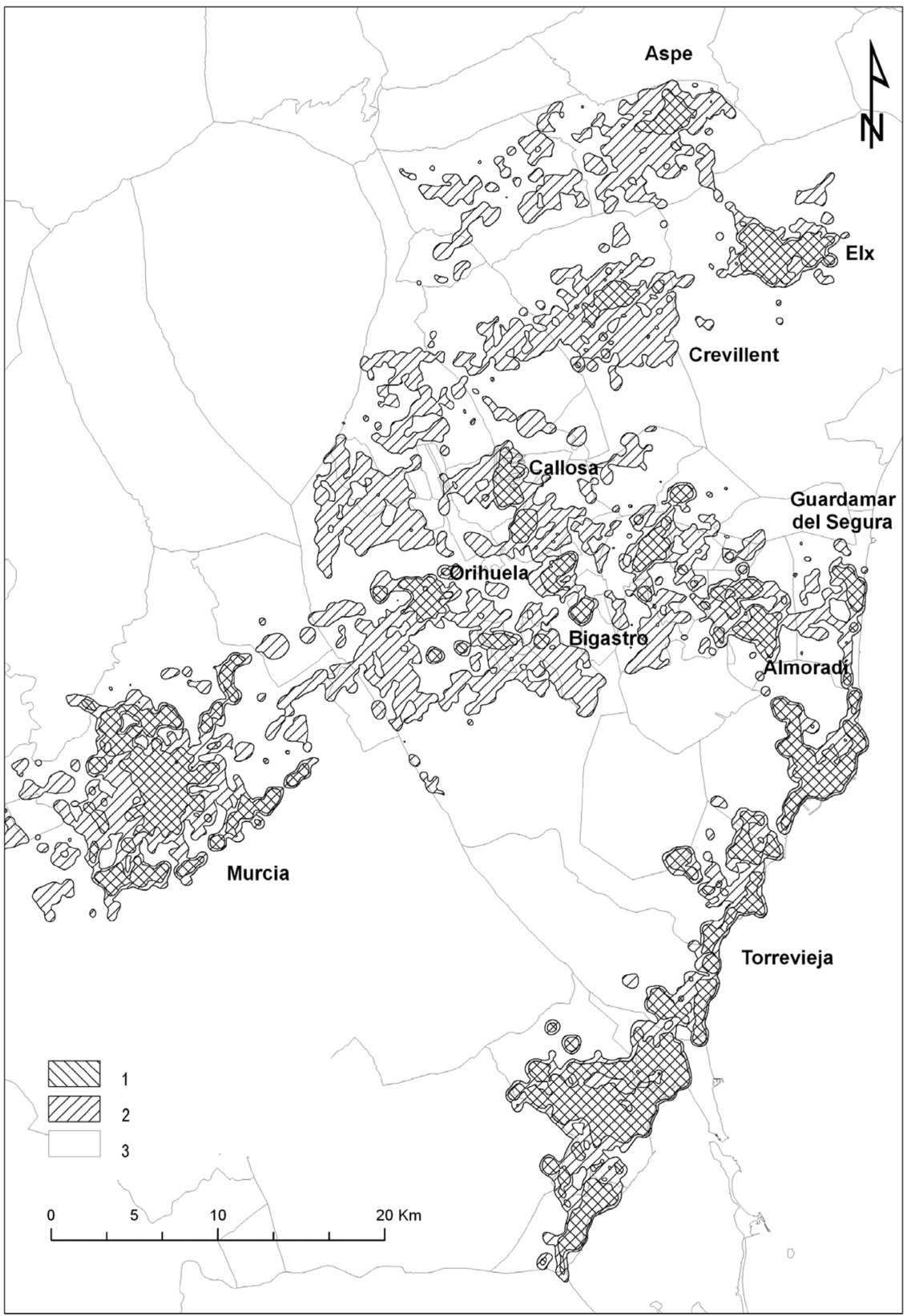

1.- Áreas urbanas, 2.-Continuo urbano de Orihuela-Elx, 3.-Término municipal. Fuente: Elaboración propia a partir de Teleatlas. 
Figura 4

ÁREAS URBANO-METROPOLITANAS INCLUIDAS EN EL CONTINUO URBANO DE GANDIA

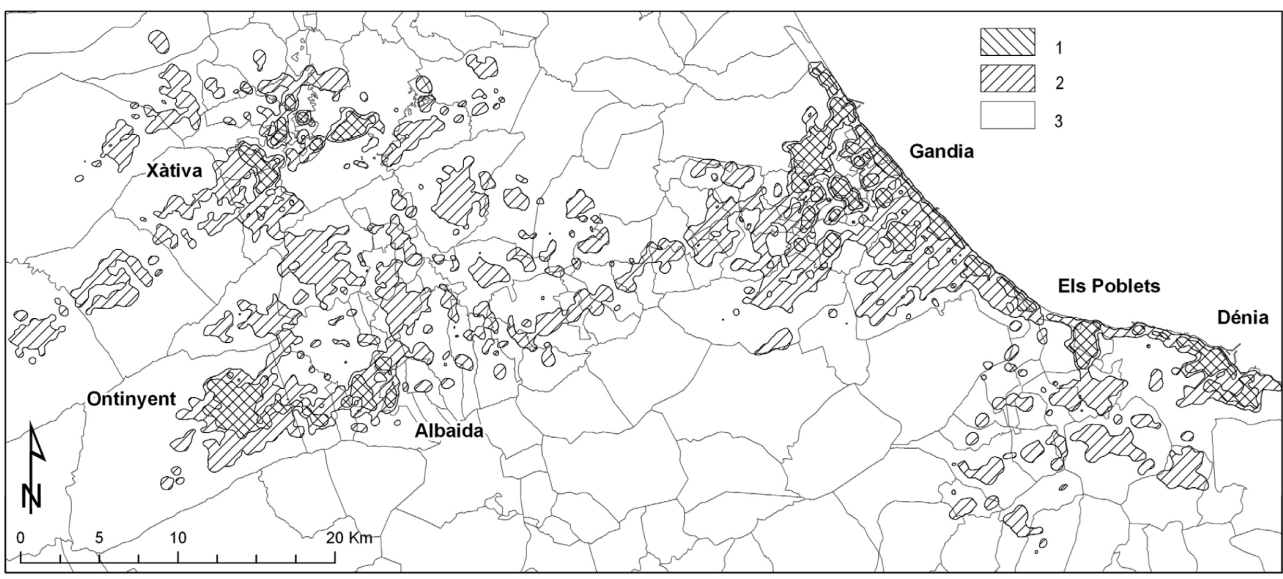

1.- Áreas urbanas, 2.-Continuo urbano de Gandia, 3.-Término municipal. Fuente: Elaboración propia a partir de Teleatlas.

Figura 5

LITORAL ALICANTINO: CONTINUOS URBANOS DE ALICANTE, BENIDORM Y XÀBIA

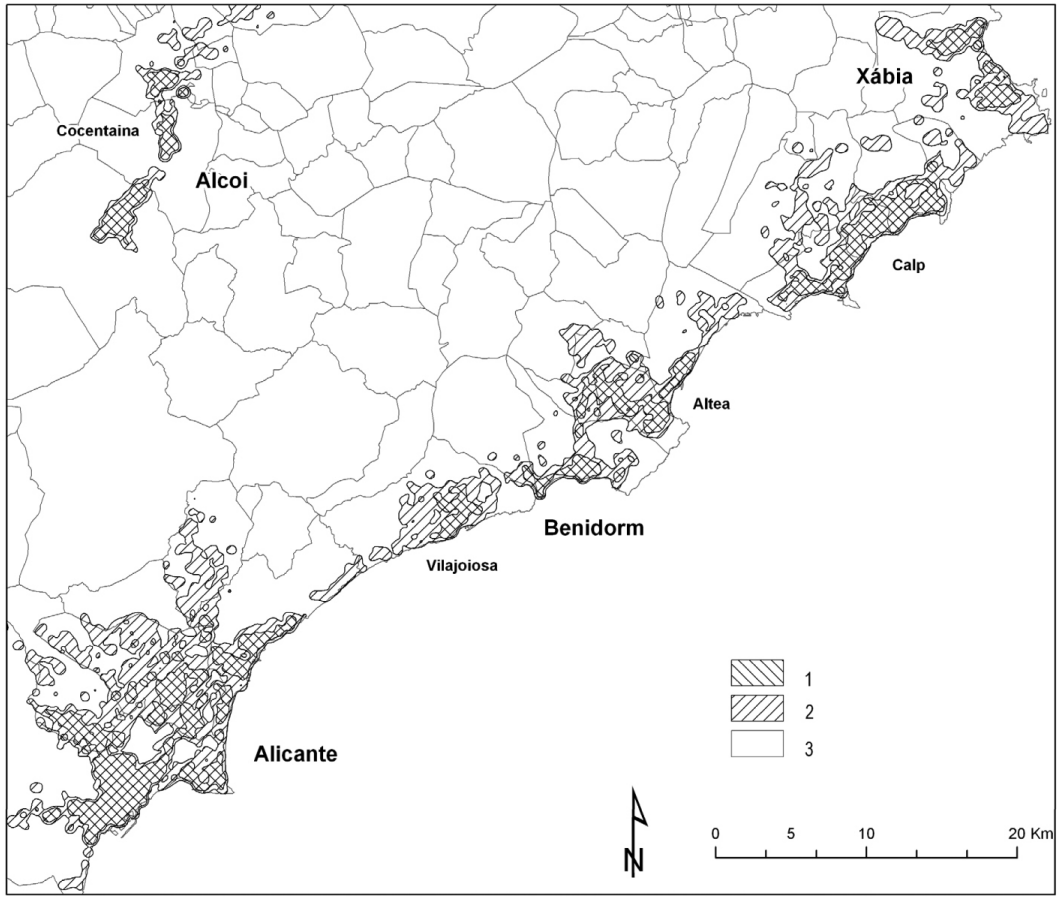

1.- Áreas urbanas, 2.- Continuos urbanos, 3.-Término municipal. Fuente: Elaboración propia a partir de Teleatlas. 
Figura 6

LITORAL CASTELLONENSE. CONTINUOS URBANOS DE CASTELLÓ, BORRIANA, BETXÍ, ONDA, LA VALLD'UIXÓ Y MONCOFA

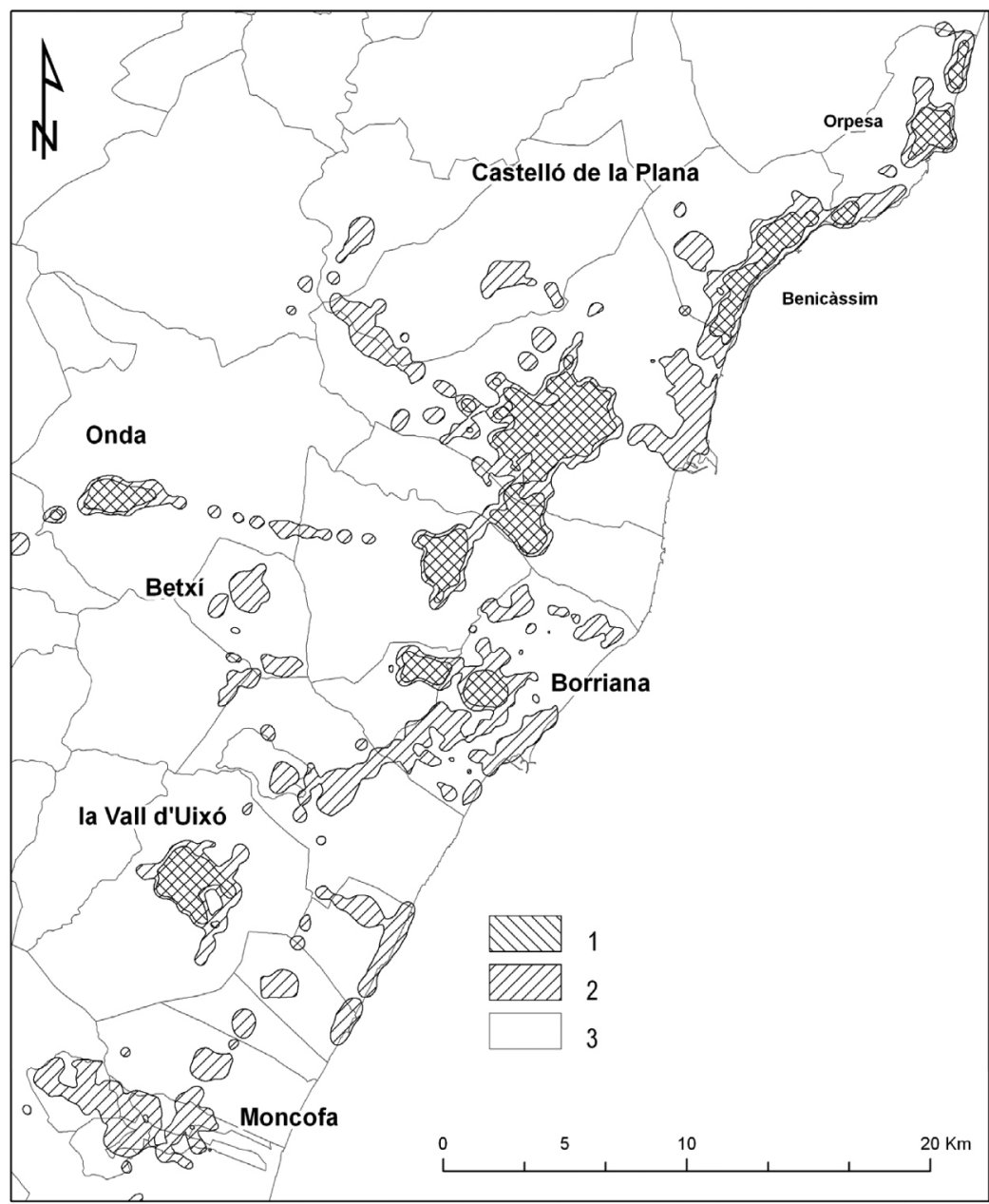

1.- Áreas urbanas, 2.- Continuos urbanos, 3.-Término municipal. Fuente: Elaboración propia a partir de Teleatlas.

Como ocurría en el caso de las Áreas Urbanas, también a esta escala es posible observar la gran extensión que los tejidos urbanos discontinuos tienen en los Continuos Urbanos del litoral meridional de la Comunidad Valenciana: Santa Pola (40\%), Orihuela-Elx (46\%), Benidorm (64\%), Xàbia-Altea (89\%). Las cifras alcanzadas por este tipo de territorios queda siempre por encima de la media (39\%), tanto de las principales aglomeraciones (Valencia, $31 \%$ ), como de los espacios urbanos del interior y norte de la Comunidad (Alcoi, 16\%; Borriana-Nules, 18\%; Elda-Petrer, 31\%; Castelló, 31\%). En el litoral meridional, la extensión de estas tipologías, junto con la proliferación de segundas residencias en espacios liga- 
Figura 7

PORCENTAJE DEL TEJIDO URBANO DISCONTINUO SOBRE EL TEJIDO URBANO TOTAL EN LOS CONTINUOS URBANOS DELIMITADOS

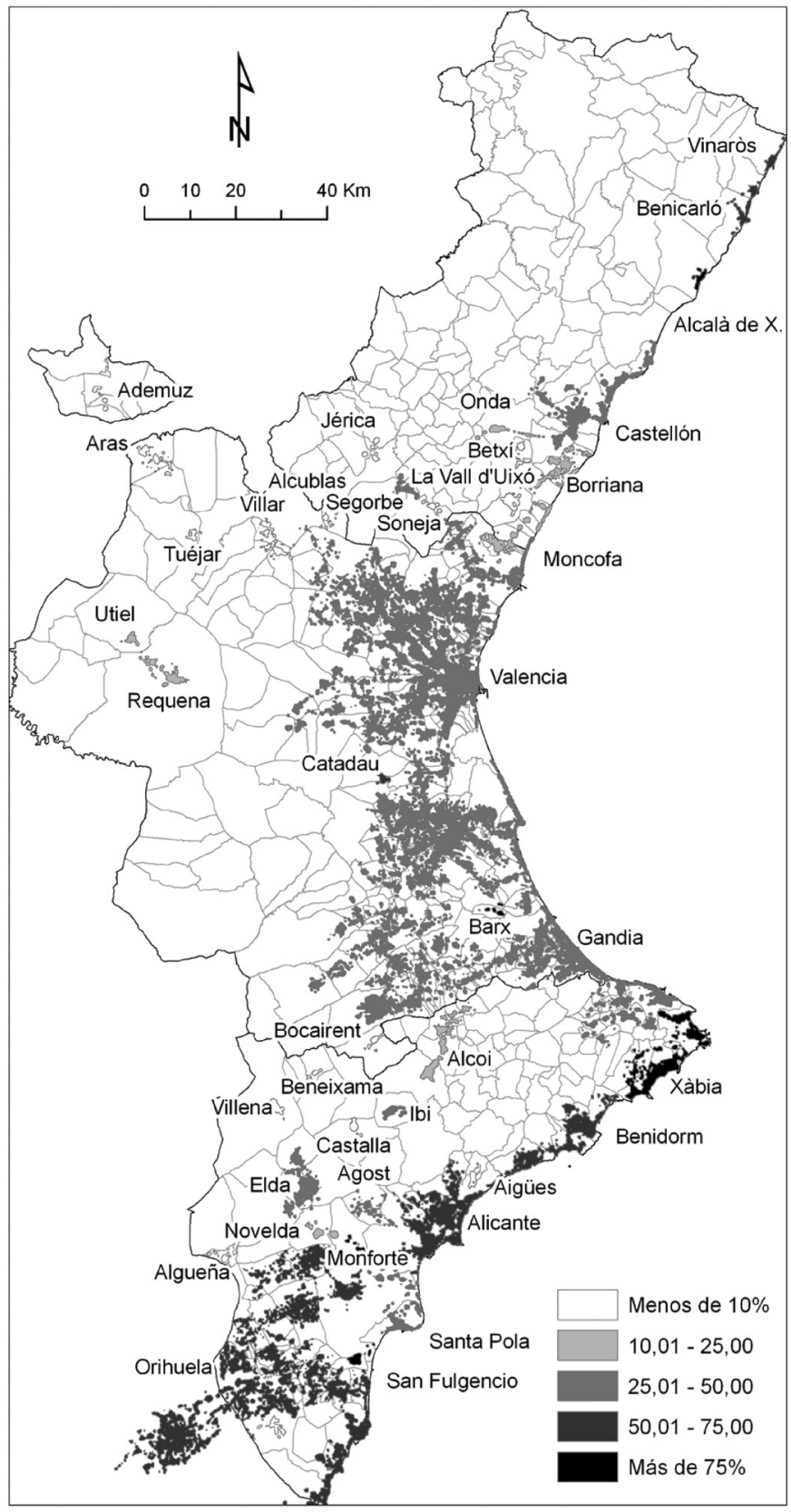

Fuente: Elaboración propia a partir de Teleatlas y CLC 2006. 
dos al turismo, ha llevado a un consumo de espacio muy elevado con densidades muy bajas en relación a la población residente; así, si la densidad poblacional media de los Continuos Urbanos delimitados es de 16 habitantes por hectárea, en el litoral meridional encontramos densidades siempre muy inferiores: Gandia (10 habs/ha), Altea-Xàbia (11 habs/ha), o Santa Pola (10 habs/ha). Como notable excepción, merece la pena destacar el caso del Continuo Urbano de Benidorm, que, con 24 habs/ha, muestra un modelo de ocupación más denso y sostenible (ver fig. 7).

\section{Caracterización de los espacios urbanos a partir de indicadores de densidad de red viaria}

Aunque en el apartado anterior se han realizado algunas observaciones basadas en la información de usos del suelo procedente de la cartografía CORINE, en este capítulo caracterizaremos morfológicamente los espacios urbanos a partir del propio índice de densidad de la red de comunicaciones, partiendo como siempre del supuesto de que éste es un indi-

Tabla 4

CARACTERÍSTICAS DE LAS PRINCIPALES ÁREAS URBANAS A PARTIR DE INDICADORES DE LA RED

\begin{tabular}{|c|c|c|c|c|c|c|c|c|}
\hline \multirow[b]{2}{*}{$\begin{array}{c}\text { Área } \\
\text { Urbana }\end{array}$} & \multicolumn{4}{|c|}{ Densidad de la red (Intersecciones/Km²) } & \multicolumn{4}{|c|}{$\begin{array}{c}\text { Distribución de la superficie según densidad } \\
\text { de la red }(\%)\end{array}$} \\
\hline & $\begin{array}{c}\text { Valor } \\
\text { máximo }\end{array}$ & Media & $\begin{array}{l}\text { Coeficiente } \\
\text { de Varia- } \\
\text { ción }\end{array}$ & Mediana & $\begin{array}{l}\text { Menos de } \\
150 \text { inter- } \\
\text { sec./Km² }\end{array}$ & $\begin{array}{c}\text { Entre } 150 \\
\text { y } 250 \text { inter- } \\
\text { sec./ } / \mathbf{K m}^{2}\end{array}$ & $\begin{array}{c}\text { Más de } \\
250 \text { inter- } \\
\text { sec./Km² }\end{array}$ & Total \\
\hline Valencia & 932 & 204 & 45 & 181 & 35,7 & 38,7 & 25,5 & 100,0 \\
\hline Alicante & 651 & 181 & 47 & 152 & 49,0 & 33,7 & 17,3 & 100,0 \\
\hline Torrevieja & 700 & 198 & 48 & 168 & 41,5 & 35,7 & 22,9 & 100,0 \\
\hline Gandia & 570 & 178 & 41 & 153 & 48,1 & 35,5 & 16,4 & 100,0 \\
\hline Calp & 381 & 150 & 29 & 138 & 61,7 & 34,7 & 3,7 & 100,0 \\
\hline Castellón & 574 & 214 & 43 & 197 & 30,8 & 39,0 & 30,2 & 100,0 \\
\hline Almoradí & 469 & 180 & 40 & 158 & 45,9 & 37,1 & 17,0 & 100,0 \\
\hline Alzira & 525 & 176 & 48 & 140 & 55,5 & 26,6 & 17,9 & 100,0 \\
\hline Ontinyent & 498 & 156 & 43 & 136 & 64,5 & 27,6 & 7,9 & 100,0 \\
\hline Altea & 632 & 150 & 47 & 129 & 71,2 & 21,8 & 7,0 & 100,0 \\
\hline Elda & 582 & 239 & 50 & 206 & 34,3 & 26,5 & 39,2 & 100,0 \\
\hline Elx & 574 & 216 & 44 & 193 & 27,1 & 45,9 & 27,0 & 100,0 \\
\hline Callosa de S. & 572 & 231 & 46 & 205 & 29,4 & 32,8 & 37,8 & 100,0 \\
\hline Carlet & 422 & 192 & 43 & 164 & 43,8 & 30,9 & 25,3 & 100,0 \\
\hline Xàtiva & 459 & 189 & 42 & 168 & 41,9 & 36,9 & 21,2 & 100,0 \\
\hline Xàbia & 446 & 159 & 48 & 127 & 70,7 & 16,7 & 12,6 & 100,0 \\
\hline Dénia & 437 & 161 & 49 & 126 & 69,8 & 16,0 & 14,2 & 100,0 \\
\hline Sagunt & 475 & 215 & 45 & 183 & 36,9 & 27,3 & 35,8 & 100,0 \\
\hline
\end{tabular}

Fuente: Elaboración propia a partir de Teleatlas. 
Figura 8

DISTRIBUCIÓN DE LA SUPERFICIE DE LAS ÁREAS URBANAS POR NIVELES DE DENSIDAD DE RED (INTERSECCIONES POR KMㄴ)

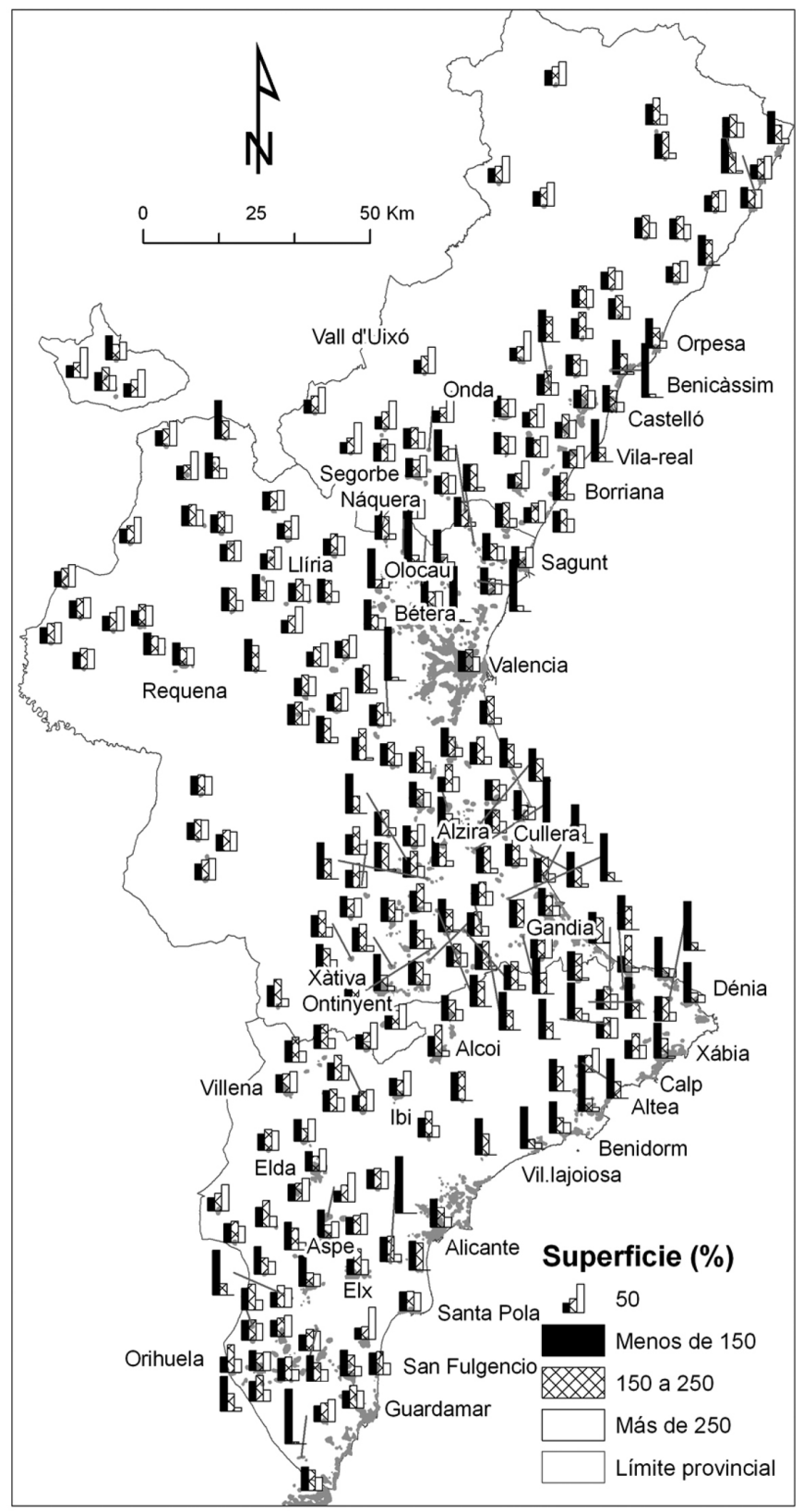

Fuente: Elaboración propia a partir de Teleatlas. 
Tabla 5

CARACTERISTICAS DE LOS PRINCIPALES CONTINUOS URBANOS A PARTIR DE INDICADORES DE LARED

\begin{tabular}{|c|c|c|c|c|c|c|c|c|}
\hline \multirow[b]{2}{*}{ Continuo Urbano } & \multicolumn{4}{|c|}{ Densidad de la red (Intersecciones/Km²) } & \multicolumn{4}{|c|}{\begin{tabular}{|c|} 
Distribución de la superficie según densidad \\
de la red $(\%)$
\end{tabular}} \\
\hline & $\begin{array}{c}\text { Valor } \\
\text { máximo }\end{array}$ & Media & \begin{tabular}{|c|}
$\begin{array}{c}\text { Coeficiente } \\
\text { de } \\
\text { Variación }\end{array}$ \\
\end{tabular} & Mediana & $\begin{array}{c}\text { Menos de } \\
60 \text { Inter- } \\
\text { sec./Km² }\end{array}$ & \begin{tabular}{|l|} 
Entre 60 y 150 \\
Intersec./Km²
\end{tabular} & \begin{tabular}{|c|} 
Más de 150 \\
Intersec./ \\
$\mathbf{K m}^{2}$
\end{tabular} & Total \\
\hline Valencia & 932 & 95 & 79 & 65 & 44,0 & 40,8 & 15,2 & 100 \\
\hline Orihuela-Elx & 805 & 111 & 83 & 74 & 36,6 & 42,5 & 20,9 & 100 \\
\hline Gandia & 570 & 90 & 69 & 66 & 42,5 & 44,5 & 12,9 & 100 \\
\hline Alicante & 651 & 110 & 71 & 85 & 27,9 & 52,3 & 19,8 & 100 \\
\hline Benidorm & 632 & 93 & 67 & 76 & 31,7 & 58,4 & 9,9 & 100 \\
\hline Xàbia & 446 & 100 & 58 & 84 & 28,4 & 57,4 & 14,3 & 100 \\
\hline Castellón & 574 & 125 & 69 & 95 & 24,8 & 47,1 & 28,1 & 100 \\
\hline Elda & 608 & 134 & 88 & 82 & 32,3 & 41,0 & 26,7 & 100 \\
\hline Santa Pola & 487 & 95 & 75 & 69 & 40,5 & 45,2 & 14,3 & 100 \\
\hline Burriana & 513 & 99 & 87 & 61 & 49,7 & 33,3 & 17,0 & 100 \\
\hline Alcoi & 469 & 113 & 66 & 87 & 30,0 & 44,5 & 25,5 & 100 \\
\hline
\end{tabular}

Fuente: Elaboración propia a partir de Teleatlas.

cador eficaz para caracterizar y comparar la morfología de las áreas urbanas. Las tablas 4 y 5 muestran los principales indicadores estadísticos a escala de áreas y regiones urbanas, respectivamente.

De los estadísticos calculados, sólo el valor máximo de densidad de intersecciones alcanzado en cada Área o Continuo Urbano guarda cierto grado de asociación positiva con su extensión superficial; por tanto, las variaciones observadas no pueden relacionarse con la magnitud del fenómeno urbano, sino más bien con el modelo territorial adoptado.

Esto se constata de forma especialmente evidente en la escala de Área Urbana; en este caso tanto los índices medios de densidad viaria como la distribución de superficies en función de la densidad muestran una doble dicotomía interior/litoral y norte/sur, de forma que los núcleos urbanos del interior y del norte de la región tienen densidades medias más elevadas y, por tanto, un modelo más denso, mientras que las áreas urbanas ubicadas en el litoral y/o en la mitad meridional de la región, muestran densidades medias más reducidas y por tanto un predominio de los modelos morfológicos de baja densidad.

Así, las Áreas Urbanas que muestran un mayor grado de dispersión son las ubicadas en el litoral alicantino (Calp, Altea, Vilajoiosa, Gata, Xàbia, Pilar de la Horadada, Beniarbeig, Albatera), o en el entorno septentrional del Área Metropolitana de Valencia (Olocau, Náquera). También presentan modelos muy dispersos algunas de las pequeñas áreas urbanizadas de las comarcas de la Ribera, la Vall d'Albaida y la Costera (Manuel, Montixelvo, Monserrat, Alberic, Guadaséquies). 
Figura 9

DISTRIBUCIÓN DE LA SUPERFICIE DE LOS CONTINUOS URBANOS POR NIVELES DE DENSIDAD DE RED (INTERSECCIONES POR KM²)

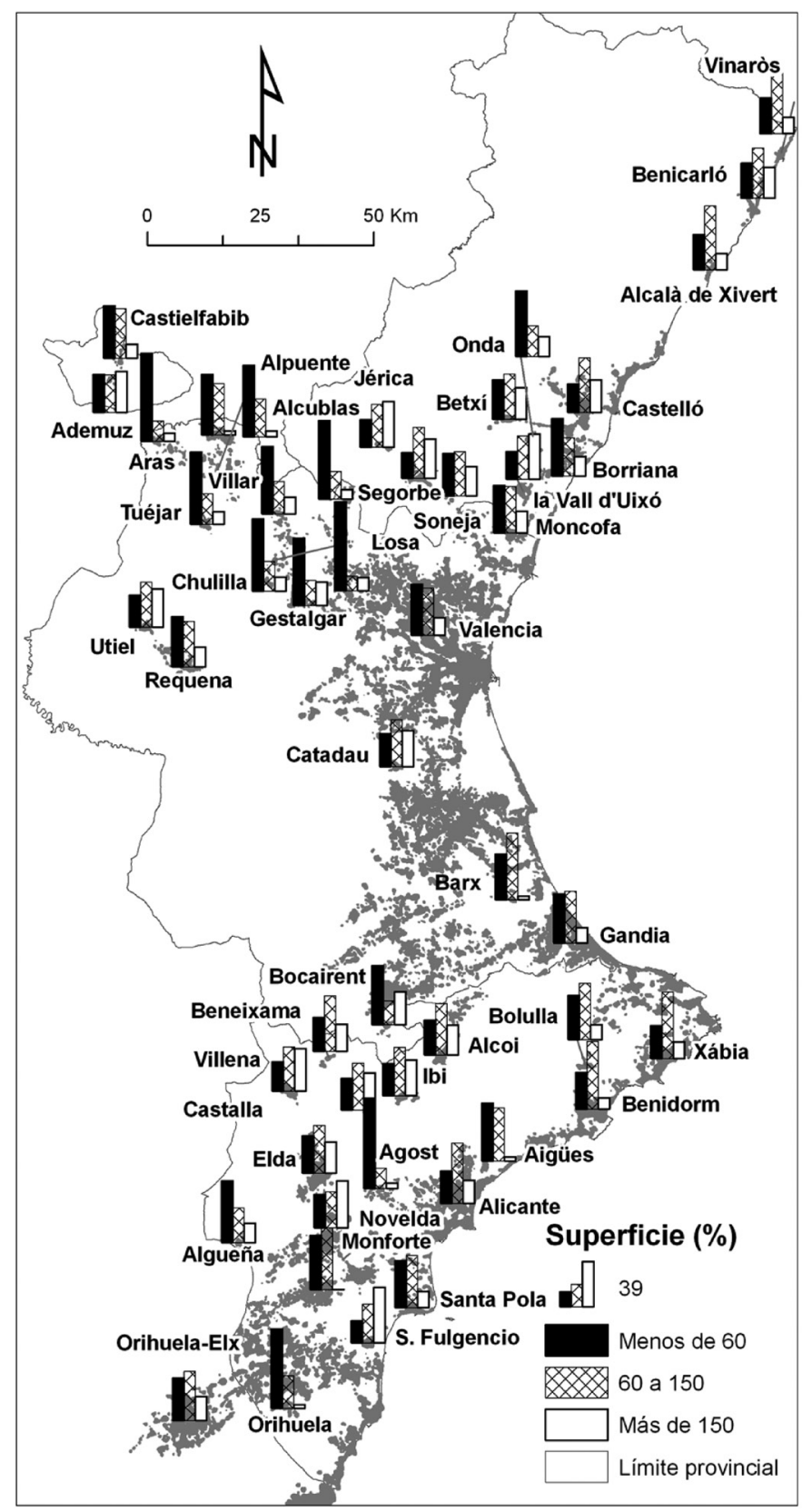

Fuente: Elaboración propia a partir de Teleatlas. 
Por el contrario, los modelos más compactos corresponden, además de a las Áreas Metropolitanas de Valencia y Castellón, a ciudades medianas y núcleos del interior de las provincias de Castellón (la Vall d'Uixó, Segorbe, l'Alcora, Caudiel, Betxí, Vilafranca, Benasal, Morella), Valencia (Utiel, Cheste, Chiva, Villar del Arzobispo, Bocairent, Ayora, Chulilla, Aras, Titaguas) y Alicante (Elda, Villena, Ibi, Novelda, Monòver, Sax, Castalla, Banyeres, Monforte). En el marco de este predominio generalizado de la compacidad urbana, es posible apreciar también una tendencia al aumento relativo de los espacios de urbanización dispersa conforme nos desplazamos del norte al sur de la región (ver figura 8).

Esta misma pauta general (dicotomía norte/sur e interior/litoral) se confirma en términos generales para el caso de los Continuos Urbanos. Así, como podemos ver en la tabla 5, los valores medios de dispersión más elevados los encontramos en Gandia, Benidorm, Valencia, Santa Pola, Borriana y Xàbia. En contraste, las Áreas de Elda y Castellón muestran elevados índices de compacidad, mientras que los Continuos Urbanos de Alcoi, Alicante y OrihuelaElx muestran valores próximos a la media.

Sin embargo, en este caso, el uso de un umbral de densidad más reducido y su desigual extensión territorial hace aumentar las diferencias entre Continuos Urbanos y en el interior de éstos (ver figura 9). La entidad y el carácter de los procesos de suburbanización y urbanización dispersa, así como el modelo territorial de los centros urbanos incluidos en la región introducen una mayor variación de situaciones.

En resumen, si tenemos en cuenta tanto el índice medio de densidad como la diversidad interna medida por el coeficiente de variación, podemos diferenciar cuatro tipos de Continuos Urbanos (ver fig. 10):

a) Continuos Urbanos homogéneamente dispersos (promedio de densidad y coeficiente de variación por debajo de la media). Se trata de zonas que incluyen tanto áreas urbanas de carácter poco denso como espacios de urbanización dispersa de carácter turístico o de segunda residencia. En su mayor parte, se ubican en las zonas litorales de las provincias de Alicante y Castellón (Xàbia, Vinarós, Alcalá de Xivert, Benidorm, Santa Pola, Orihuela, Aigües, Moncofa...). También forma parte de este grupo el Continuo Urbano de Gandia, que incluye, junto con su Área Urbana, extensos tejidos urbanos dispersos ubicados tanto en el litoral (Marina Alta) como en el interior (urbanización dispersa de las comarcas de la Vall d'Albaida y la Costera).

b) Continuos Urbanos con predominio de la dispersión pero con importantes diferencias internas (índice medio muy bajo y elevado coeficiente de variación). Se trata de espacios en donde predominan los procesos de urbanización dispersa, pero que incluyen también núcleos urbanos relativamente compactos. Según la importancia de estos núcleos centrales, podemos diferenciar entre:

- Continuos Urbanos que cuentan con núcleos urbanos centrales potentes, y que incluyen tanto áreas de urbanización dispersa como espacios centrales más densos: Valencia, Elx, Requena.

- Espacios interiores, con núcleos urbanos pequeños de carácter compacto, que se ven afectados por procesos de suburbanización en gran parte de carácter externo o periférico al área: Chulilla, Alcublas, Villar, Aras, Losa del Obispo, Gestalgar..., en la periferia del Continuo Urbano de Valencia; o Borriana, Betxí, en la periferia del Continuo Urbano de Castellón. 
Figura 10

TIPOLOGÍA DE CONTINUOS URBANOS SEGÚN DENSIDAD MEDIA DE LARED Y COEFICIENTE DE VARIACIÓN

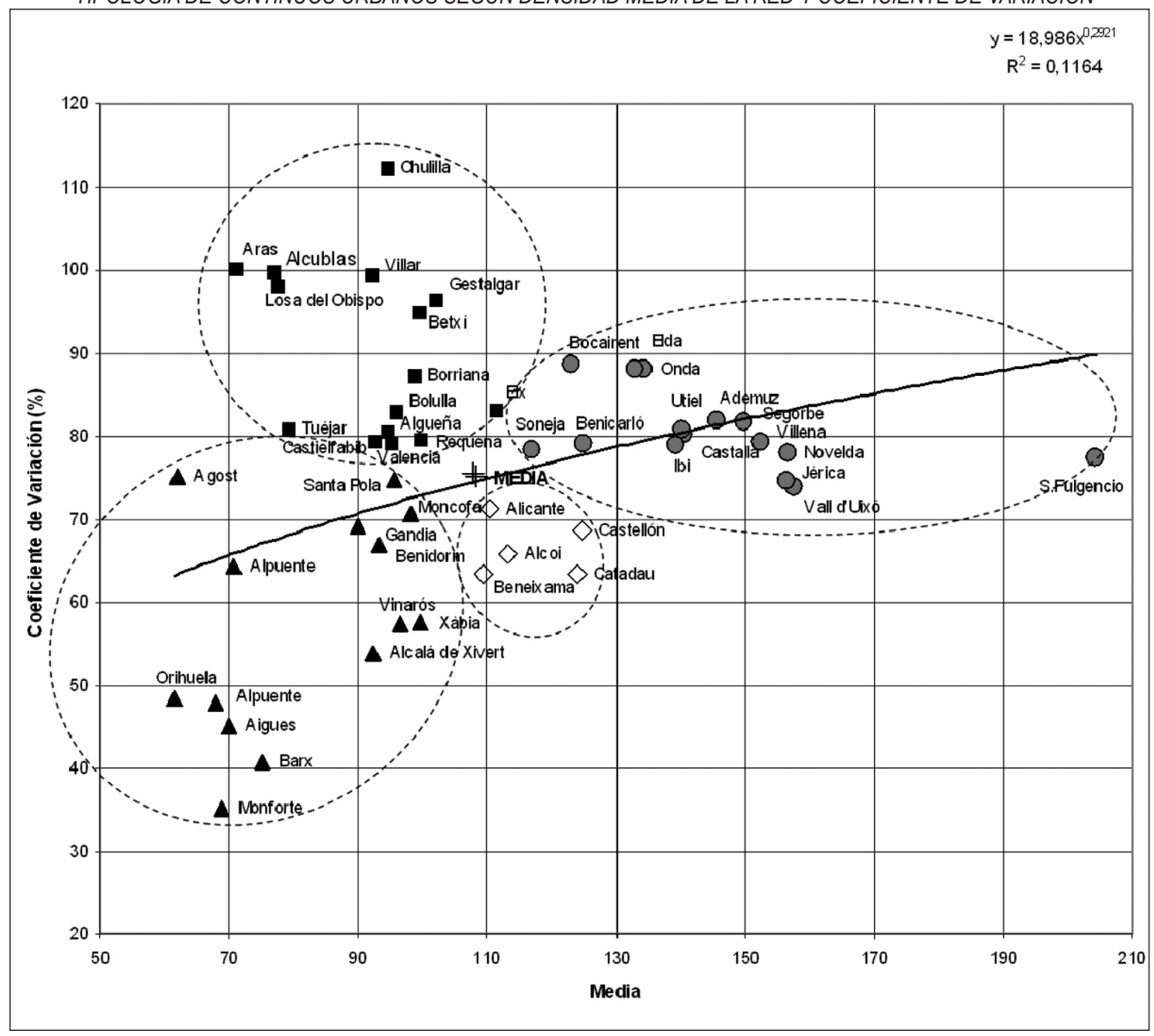

c) Continuos Urbanos homogéneamente compactos (índice de densidad superior a la media, y coeficiente de variación por debajo de la media): Se trata de núcleos urbanos compactos relativamente importantes, pero que experimentan procesos de suburbanización limitados: Alicante, Alcoi, Castellón...

d) Continuos Urbanas compactos, pero con algunas desigualdades internas generadas por procesos de urbanización de baja densidad (promedio de densidad y coeficiente de variación en torno o ligeramente por encima de la media). En su mayor parte, se trata de los constituidos en torno a ciudades medianas del interior castellonense y alicantino que han experimentado procesos de suburbanización en su entorno próximo. El valor del coeficiente de variación depende de la intensidad de estos procesos y/o de la importancia relativa del núcleo central: máximos en Onda, Elda y Bocairent, menores en Ademuz, Benicarló, Segorbe, Utiel, Castalla, Ibi, Villena, Soneja, Novelda, Utiel, y muy reducidos en Jérica y la Valld'Uixó, 


\section{CONCLUSIONES}

La metodología propuesta, basada en la densidad de intersecciones de la red viaria, es perfectamente válida para captar el fenómeno urbano y presenta ventajas específicas para la identificación e individualización de las áreas que pueden constituirse en unidades del análisis territorial. El método de delimitación ha permitido definir espacios urbanizados desde una nueva perspectiva, la del espacio construido. Las limitaciones de CORINE para el análisis de pequeños espacios urbanizados quedan pues superadas.

Las áreas urbanas así delimitadas son espacios construidos y vertebrados a través de la red de calles y carreteras; por ello, aunque se trata de una delimitación de naturaleza morfológica, puede considerarse también que las áreas resultantes poseen también una realidad funcional en la medida en que la propia densidad de la red de comunicaciones está en la base de su definición y articulación. Es por esto que las unidades territoriales así constituidas resultan especialmente adecuadas para el análisis de los procesos urbanos actuales, complementando, que no sustituyendo, desde una perspectiva morfológico-funcional las visiones que ofrecen las delimitaciones puramente funcionales.

El propósito de este artículo ha sido mostrar la viabilidad de las delimitaciones realizadas para el análisis y medición de procesos urbanos ligados a la extensión de la ciudad difusa, tales como la extensión del tejido urbano discontinuo o de espacios productivos y de servicios especializados. Asimismo, se ha realizado una primera caracterización de los espacios delimitados en función de los propios indicadores de densidad de la red, lo que ha permitido diferenciar entre las Áreas y Continuos Urbanos en donde predominan las dinámicas de urbanización de baja densidad de las que presentan morfologías más densas y aquéllas de carácter mixto. El modelo territorial predominante en la región, caracterizado por una doble dicotomía interior/litoral y norte/sur (modelos urbanos más densos en el interior y norte de la región, frente a predominio de los modelos morfológicos de baja densidad en el litoral y/o en la mitad meridional de la región) queda reflejado a través de los indicadores utilizados.

Por tanto, consideramos que, una vez ajustados los índices de densidad para distintas realidades territoriales y usos, y contando siempre con información actualizada de evolución del viario, esta herramienta podría permitir monitorizar en tiempo real los procesos de urbanización difusa sin necesidad de tener que esperar a la actualización de la cartografía de usos del suelo.

\section{BIBLIOGRAFÍA}

BORRUSO, G. (2003): Network density and the Delimitation of Urban Areas, Transactions in GIS, 7 (2), 177-191

CASTAÑNER, M (1994): La ciudad real en Cataluña. Las áreas de cohesión, Estudios Territoriales. Ciudad y Territorio, 99, 101-114.

CENTRO NACIONAL DE INFORMACIÓN GEOGRÁFICA (2006): CORINE LANDCOVER 2006 [en línea],

http://centrodedescargas.cnig.es/CentroDescargas/index.jsp [26 de septiembre de 2010]

FERIA, J.M. (2008): Un ensayo metodológico de definición de las áreas metropolitanas en España a partir de la variable residencia-trabajo, Investigaciones Geográficas, 46, 49-68. 
GENERALITAT VALENCIANA, CONSELLERIA D'OBRES PÚBLIQUES, URBANISME I TRANSPORTS (1995): Estrategies de vertebració territorial, Generalitat Valenciana, Valencia.

HARRIS, R.H. Y LONGLEY, P. A. (2000): New Data and Approaches for Urban Analysis: Modelling Residential Densities, Transactions in GIS, 4 (3), 217-234. http://centrodedescargas.cnig.es/CentroDescargas/buscadorCatalogo.do?codFamilia=02113

INDOVINA, F. (1998): Algunes consideracions sobre la «ciutat difusa», Documents d'Anàlisi geogràfica, 33, 21-32.

MIRALLES, C. (2002):Transporte y territorio urbano: del paradigma de la causalidad al de la dialéctica, Documents d'Anàlisi Geografica, 41, 107-120.

NAVARRO VERA, J.R., MARTÍ CIRIQUIAN, P., Y QUESADA POLO, J. (2000): Alicante: la nueva «ciudad del urbanizador», Ciudad y Territorio. Estudios Territoriales, XXXII, 126, pp. 711-725.

NEL.LO, O. (1996): Els confins de la ciutat sense confins. Estructura urbana i límits administratius de la ciutat difusa, en Castañer, A., Falgueras, M., Vicente, J.: La ciutat difusa $i$ les perifèries: experiències de planificació i gestió. Actes de les II Jornades de Geografia i Urbanisme. Girona, Universitat de Girona, p. 55-71.

OBSERVATORIO DE LA SOSTENIBILIDAD DE ESPAÑA (2006): Cambios de ocupación del suelo en España. Implicaciones para la sostenibilidad. [En línea]. Madrid: Ministerio de Fomento, <http://www.sostenibilidad-es.org/sites/default/files/_Informes/tematicos/ suelo/suelo-esp.pdf $>$. [17 de noviembre de 2010].

SALOM CARRASCO, J. Y ALBERTOS PUEBLA, J. M. (2010): Densidad de la red viaria y forma urbana: Delimitación del espacio urbano en ocho aglomeraciones españolas, en Feria Toribio, J.M. y Albertos Puebla, J.M.: La ciudad metropolitana en España: Procesos urbanos en los inicios del siglo XXI, Thomson Reuters, Pamplona, pp. 49-94.

SALOM, J. (2011): Procesos territoriales y transformaciones recientes del sistema urbano valenciano, Scripta Nova-Revista Electrónica de Geografía y Ciencias Sociales, Barcelona, vol. $15, \mathrm{n}^{\circ} 356$.

SALOM, J. Y CASADO, J.M. (2007): Movilidad cotidiana y mercados locales de trabajo en la Comunidad Valenciana, 1991-2001, Boletín de la Asociación de Geógrafos Españoles, vol. 44, pp. 5-38.

SALOM, J.; ALBERTOS, J.M.; DELIOS, E. y PITARCH, M.D. (1996): Una nueva visión del sistema urbano regional: las áreas de cohesión en la Comunidad Valenciana, en III Reunión del Grupo de Geografía Urbana de la AGE, Antequera, Grupo de Geografía Urbana de la AGE, págs. 521-532.

SALOM, J.; ALBERTOS, J.M.; DELIOS, E. y PITARCH, M.D. (1997): Las áreas de mercado de trabajo local en la Comunidad Valenciana. Una propuesta de delimitación. Estudios Territoriales. Ciudad y Territorio, 112, 335-356. 
